Draft Submission- Health Law in Canada (June 2019) - Publication Pending Final Review

\title{
A Legal Duty of Genetic Recontact in Canada
}

Adrian Thorogood*, Alexander Bernier*, Ma'n Zawati* \& Bartha Maria Knoppers*

*Centre of Genomics and Policy (CGP), Department of Human Genetics, McGill University

Suite 5200, 740 Ave Dr. Penfield, Montreal, Quebec

\section{Article Type: Original Legal Analysis}

Corresponding author: $\underline{\text { adrian.thorogood@mcgill.ca }}$

\section{Author 1-2 Sentence Bios:}

- Adrian Thorogood (BCL/LLB), is a lawyer (Ontario Bar) and LLM (Candidate) at the University of Toronto, Faculty of Law, Academic Associate at the CGP, and Regulatory and Ethics Work Stream Manager of the Global Alliance for Genomics and Health.

- Alexander Bernier (BCL/LLB) is a research assistant at the CGP.

- Ma'n Zawati (DCL- Doctor of Civil Law) is Executive Director of the CGP, and an Associate Member of the McGill Biomedical Ethics Unit.

- Bartha Maria Knoppers (PhD - Comparative Medical Law) is a Full Professor, Director of the CGP, and Canada Research Chair in Law and Medicine.

The authors have no competing interests.

The authors acknowledge they have not plagiarized any part of the article.

\footnotetext{
ABSTRACT

Our understanding of the clinical significance of genomic data is rapidly evolving. The meaning of a patient's test results can therefore change over time. Reanalysis of genomic data over time and
} 
Draft Submission- Health Law in Canada (June 2019) - Publication Pending Final Review

patient recontact offer an opportunity to improve patient health. But are physicians legally responsible to do so? Professional associations worldwide are outlining best practices for genetic recontact. To inform Canadian guidelines and courts faced with this issue, we review Canadian case law to determine if there is a likely doctrinal basis for judicial recognition of a duty to recontact in genetics. Foreign guidelines or malpractice case law may not adequately reflect the peculiarities of Canada's diverse legal and public health systems. A threshold consideration is the duration of the physician-patient relationship, seeing as physicians do not generally owe legal duties to former patients. This legal relationship endures according to the need for continued care as well as the subjective perspectives of both physician and patient. Satisfying these criteria in genetics can be difficult because of interpretative uncertainty or the absence of definitive intervention. Moreover, coordination of genetic analysis, communication, and follow-up care between healthcare professionals is complex, leading to problems of incomplete hand-off between laboratories, specialists, and primary care providers. The key challenge for plaintiffs will be to establish fault, that is, breach of a duty. Physicians in Canada traditionally have duties to diagnose, inform, follow-up and of confidentiality. We conclude that a legal duty of genetic recontact is only likely in specific circumstances where physicians acquire updated genetic information of clear health significance. This remains unlikely unless health systems or laboratories commit to systemic and adaptive reanalysis. This may change with the confluence of whole genome testing and advanced health information technologies (HIT). Whole genome sequences include millions of individual genetic variants and in turn, millions of opportunities for adaptive reinterpretation. HIT enables data sharing between laboratories, automated reanalysis of genomic test results, and new lines of communication with physicians and patients. Fundamentally, it is only health systems or institutions that can provide the infrastructure needed to adapt patient care in step with an evolving genetic knowledgebase. 
Draft Submission- Health Law in Canada (June 2019) - Publication Pending Final Review

\section{Table of Contents}

INTRODUCTION

THE BOUNDS OF THE PHYSICIAN-PATIENT RELATIONSHIP 6

A. Duration $\quad 6$

B. Coordination of Care $\quad 8$

C. A Fiduciary Relationship 11

THE TRADITIONAL DUTIES OF PHYSICIANS IN GENETICS 13

A. The duty to diagnose / treat 13

B. The duty to inform $\quad 15$

$\begin{array}{lr}\text { C. The duty to follow-up } & 18\end{array}$

D. The duty of confidentiality 21

RECENT TRENDS IN PROFESSIONAL GUIDELINES $\quad 22$

SUMMARY

DISCUSSION: The impact of genomic and health information technologies 26

$\begin{array}{ll}\text { CONCLUSION } & 30\end{array}$ 
Draft Submission- Health Law in Canada (June 2019) - Publication Pending Final Review

\section{INTRODUCTION}

Medical practice as traditionally perceived requires a determinate diagnosis to be made with incomplete information. The patient consults a professional who diagnoses, treats, and ensures the performance of post-treatment follow-up. Symptoms may change or persist, determining the need for continued care. Genetic practice is a different endeavor. Barring limited epigenetic changes, the content of a patient's genome is stable over a lifetime, and unlike their visible symptoms, is vast in its quantum. Moreover, the interpretation of each individual's several million genetic variants can often change in step with the rapid pace of genomic research. As the New York Times recently reported, "Laboratories frequently "reclassify" genetic mutations. But there is no reliable system for telling patients or doctors that the results of their genetic tests are no longer valid."1

Genetic testing includes tests for Mendelian (single gene) disease, predisposition testing (e.g., BRCA1/2), and pharmacogenetic tests that inform drug efficacy, risk and dosage. ${ }^{2}$ Genomic malpractice refers to liability for the negligent performance of genetic testing. Liability can arise where physicians fail to order an indicated genetic test, misinterpret a test result, or fail to communicate a result to a patient. ${ }^{3}$ The United States has seen a slow rising tide of genomic malpractice, though not the tsunami that has often been predicted. ${ }^{4}$ This is likely due to a number of factors, the foremost being the slow uptake of genomic medicine, attributed in turn to limited evidence of clinical utility, physician unfamiliarity, and lack of clinical decision-support infrastructure. ${ }^{5}$ Another factor is that genomic malpractice lawsuits tend to be discouragingly risky, drawn-out and complex, though there is a relatively high plaintiff success rate, and average payouts are an order of magnitude higher than traditional malpractice cases. ${ }^{6}$ In short, liability risk remains an important factor that "could be enormously influential in the update and future direction of genomic medicine." 7 There is also the possibility for novel legal claims, including failures to warn relatives of 
Draft Submission- Health Law in Canada (June 2019) - Publication Pending Final Review

genetic risks (even where the information is confidential to the patient) ${ }^{8}$, to return incidental or secondary findings, ${ }^{9}$ or to update results over time. ${ }^{10}$ We limit our discussion to this latter subject, except to explore how these emerging duties might be mutually reinforcing.

For our purposes, "recontact" means contacting a patient or former patient to update them about new medical meaning relating to their genetic test results. ${ }^{11}$ The trigger for recontact is typically genetic reinterpretation of a variant by a laboratory or physician based on new publications or patient observations, or the identification of a new medically relevant variant. ${ }^{12}$ Clinically significant reinterpretations are when variants are reclassified from pathogenic (or likely pathogenic) to uncertain/likely benign/benign or vice-versa. ${ }^{13}$ Emerging empirical data suggests the frequency of clinically significant reinterpretation is non-trivial, ${ }^{14}$ and may be increased by data sharing between clinical laboratories, a collaborative form of quality control. ${ }^{15}$

Changing interpretations are a unique feature of genomic medicine that challenge the traditional assumptions of medical liability law. It is difficult to predict how Canadian courts might delineate the boundaries of the physician's legal obligations to reanalyze test results, and/or recontact patients to inform them of new interpretations. To date, no comprehensive review of the potential for such liability in Canadian law has been attempted. With a view to informing judicial decision-making and supporting the development of professional guidelines tailored to the Canadian healthcare and legal context, we consider if Canadian case law supports a duty to recontact a patient or former patient about an updated test result.

Our analysis proceeds in two steps. First, we review cases defining the duration of the physician-patient relationship. The termination of this relationship, e.g. in the case of former patients, is likely to extinguish legal duties. Second, where a legal relationship (i.e. duty of care) exists, we consider if the traditional legal duties of the physician provide grounds to support a duty of genetic 
Draft Submission- Health Law in Canada (June 2019) - Publication Pending Final Review

recontact. Courts are more likely to establish liability by analogy to existing duties than to discover new ones. ${ }^{16}$ In our discussion, we argue that it is unhelpful to frame genetic recontact as a matter of individual responsibility, or (by extension) to expect tort law to solve challenges arising from the changing meaning of genetics. Rather, genetic recontact is largely a matter of health system and health information technologies (HIT) design. Only in a continuously learning health-care system will patients have abundant opportunities to benefit from adaptive interpretation. ${ }^{17}$

\section{THE BOUNDS OF THE PHYSICIAN-PATIENT RELATIONSHIP}

An important threshold issue to consider is the duration of the physician-patient relationship, seeing as physicians do not generally owe legal duties to former patients. We argue, however, that genetics can bring additional indeterminacy to the duration of this relationship. Another is the coordination of care between healthcare professionals. Genetic analysis, communication, and followup care can involve complex coordination and communication, blurring the bounds where one physician's duties end and another's begin. We also briefly discuss the fiduciary nature of this relationship and its implications for genetic recontact.

\section{A. Duration}

Physicians have a special legal relationship with their patients, referred to as "duty of care." While the existence of a duty of care is typically uncontroversial in medical negligence cases, the duration of physician-patient relationship is a key threshold question in the context of genetic recontact. Presumably, the termination of this relationship extinguishes the physician's legal duties. In determining whether or not a physician-patient relationship exists, courts in Canada consider the following contextual factors:

a) Whether or not both the patient and physician subjectively consider they are in a physicianpatient relationship; ${ }^{18}$ and 
Draft Submission- Health Law in Canada (June 2019) - Publication Pending Final Review

b) Whether the continued care of the physician is required in the circumstances, according to the standards of "good medical practice."19

The physician-patient relationship can be either "enduring" or "episodic" (beginning and terminating on different instances of treatment). An enduring relationship may be found even absent continued treatment or consultation if only the patient considers the relationship to be ongoing. ${ }^{20}$ The physician-patient relationship can also endure where the patient passively relies on prior services rendered by the physician, for instance where a "continuing, open prescription" continues to be available to the patient. $^{21}$

\section{Implications of genetics and genomics}

Termination of the physician-patient relationship may be more indeterminate in genetics. A germline (heritable) genetic test result is relatively stable over an individual's lifetime. It therefore remains an active concern until the patient has received some form of follow-up (e.g., treatment, preventative surgery, increased monitoring, or reproductive counselling). The follow-up may itself be ongoing. In many cases, no definitive intervention will be available. Patients may also delay interventions for personal reasons.

Many genetic test results are too uncertain to form the basis for medical intervention, such as those returning variants of unknown significance (VUS). ${ }^{22}$ This has led to debates over whether or not, and how, to report VUS. ${ }^{23}$ A reasonable expectation, however, might be for health professionals to monitor VUS over time until the patient can be offered a more definitive result. And given the evidence presented above that even definitive variant classifications are updated over time, there is potentially good reason to actively monitor all test results over time.

It is particularly with the advent of whole genome testing that the bounds of the physicianpatient relationship become blurred. The true potential of whole genome testing is not as a one-off 
Draft Submission- Health Law in Canada (June 2019) - Publication Pending Final Review

test, but as a platform, supporting a shift towards informing whole-life care. Whole genome sequencing potentially expands the number of "live" issues across the millions of variants observed in each individual. Whole genome sequencing may additionally return a range of "secondary findings.” The US American College of Medical Geneticists' professional guidelines recommend that a list of 59 genes be actively analyzed, and pathogenic mutations in those genes be reported. An expert panel considers updates to this list every 6 months. ${ }^{24}$ Including analysis of these "secondary findings" as standard of care exposes more data points to potential clinical revision over time. Moreover, as best practices expand secondary finding gene lists over time, should past genomes undergo reanalysis? If not liability, could this encourage a new form of informational defensive medicine - the deletion or anonymization of genomic data? ${ }^{25}$

Genetic test results can remain active concerns for long stretches of time, and are often uncertain or subject to revision. Whole genome testing potentially multiplies this indeterminacy across numerous variants (e.g., the ACMG list). It may therefore be harder to identify a clear termination to physician-patient relationship in genetics and genomics. It is important to note, however, that from a public health perspective the distinction between former and current patients is not clearly relevant. Rather, the relevant factors are the clinical significance of the reinterpretation and the duration of time that has passed. In the next section we consider the blurred bounds between healthcare professionals.

\section{B. Coordination of Care}

Uncertainty over the bounds of a physician-patient relationship can also arise when care is transferred between physicians. Physicians can delegate duties to subordinates, fellow physicians and specialists, where appropriate. Delegation does not eliminate the physician-patient relationship but instead suspends it due to reliance on a third party. ${ }^{26}$ This is not a total suspension of the relationship, 
Draft Submission- Health Law in Canada (June 2019) - Publication Pending Final Review

but rather a suspension of the specific duties that have been delegated to another healthcare professional. Even where another physician takes over the totality of the patient's care, some of the referring physician's responsibilities will continue to exist. ${ }^{27}$ For instance, if the doctor has information that is of special relevance to the care of the patient, she may have a responsibility to disclose it, even if the new healthcare practitioner should be able to discover it alone. ${ }^{28}$ This remains true even if the relevance of the information is only made clear to the original physician after the patient is transferred. ${ }^{29}$

In treatment, the decision to share responsibilities among healthcare professionals can trigger additional responsibilities to ensure that the sharing does not compromise the quality of the care offered to the patient. ${ }^{30}$ These responsibilities include an obligation to communicate with other medical health professionals, both indirectly through the keeping of accurate medical records that can safely be relied on, ${ }^{31}$ and directly in ensuring that someone is responsible for all elements of treatment and care. ${ }^{32}$ Where responsibilities are appropriately divided among medical health professionals, cooperating professionals are liable only insofar as their own delineated responsibilities are not completed. ${ }^{33}$

Nonetheless, inappropriate reliance on the medical work of another professional can lead to liability. This can occur where a physician should not have relied on the work of another in discharging her obligations. Examples include relying on medical records to disclaim the need to independently diagnose the patient and determine a course of treatment, ${ }^{34}$ or when a team of physicians fail to clearly apportion responsibilities as part of a coherent treatment plan. ${ }^{35}$ This can also occur on referral of a patient to a specialist that the physician knows to be incompetent. ${ }^{36}$ Where a healthcare professional acts with "manifest incompetence," cooperating parties may be obligated to flag or rectify their negligent acts. ${ }^{37}$ Courts have recognized the potential for standards of care 
Draft Submission- Health Law in Canada (June 2019) - Publication Pending Final Review

pertaining to inter-professional cooperation across different professional orders or specialties to be entrenched in codes of conduct and guidelines. ${ }^{38}$

In Rupert $v$ Toth, remittance of test results by a specialist to a primary care physician did not discharge the duties of the specialist to the patient, as the primary care physician could not be expected to understand their significance. ${ }^{39}$ In Bain, the Court held that the delegation of a duty by an institution to a primary care physician is appropriate only when the information provided to the physician is sufficient. ${ }^{40}$ Consequently, within medical teams it may be necessary to ensure that all parties share an understanding of their respective responsibilities and are provided with sufficient information to discharge them.

In summary, the following factors tend to determine the existence or not of a physicianpatient relationship: "Is termination consistent with good medical practice? Does the physician have specialized knowledge, either medical in nature or pertaining to the patient, making him or her best placed to ensure the patient's well-being? Has the physician-client relationship been explicitly terminated, or have responsibilities been totally transferred to another healthcare professional and this has been clearly communicated to all parties?"

\section{Implications for genetics and genomics}

In assessing the bounds of physician-patient relationships, the complex coordination between primary care providers, genetic specialists, and genetics laboratories must be considered. ${ }^{41}$ GPs are more likely to provide ongoing and continuous care to patients over time; however, they have limited expertise in genetics. Geneticists tend to have episodic relationships with patients, but are of course experts in genetics. In the genetic context, care for the patient is often provided through the collaboration of general practitioners, geneticists, genetic laboratories and other healthcare professionals/entities. Coordination and clear communication of responsibilities between health-care 
Draft Submission- Health Law in Canada (June 2019) - Publication Pending Final Review

professionals is essential. Hand-off from specialist to GPs can be uncertain, as GPs typically have limited knowledge of genetics. The relationship may persist until the intervention is complete, or the patient is transferred to a family physician or other healthcare professional.

International clinical and research ethics recommendations have vacillated as to who is responsible for performing recontact. Referring to recontact in the clinical context, the American Society of Human Genetics stated in 2019 that "lines of responsibility ... were unclear" ${ }^{42}$ and simultaneously that "multidisciplinary collaboration" 43 is critical to its performance. Also in 2018 , the European Society of Human Genetics called for the coordination of responsibilities for clinical recontact between genetic specialists, patients, genetics laboratories, primary care physicians, and professional and patient associations. ${ }^{44}$ A position statement issued in 1999 by the American College of Medical Genetics suggested the primary care physician as the principal actor responsible for performing recontact, due to her proximity to the patient. ${ }^{45}$ This was updated in 2019 to clarify recontact as a fundamentally shared responsibility, with laboratories responsible for reporting variant reclassifications to ordering physicians, who should then take reasonable steps to recontact patients. ${ }^{46}$ Surprisingly, the ACMG also recommends physicians make defensive communications during consent and pre- and post- test counselling to clarify that patients are ultimately left responsible for initiating recontact. ${ }^{47}$ As we argue below, neither physicians nor patients should be left alone to drift in the genomic information deluge. Healthcare and health information technology systems will need to play a central role.

\section{A Fiduciary Relationship}

Fiduciary relationships are those where a person relinquishes their own autonomy in certain matters to another person. In Canada, the physician-patient relationship is a "fiduciary relationship."48 In the physician-patient relationship, the patient relinquishes their autonomy in 
Draft Submission- Health Law in Canada (June 2019) - Publication Pending Final Review

medical matters to the physician. Fiduciary relationships also recognize a power imbalance. ${ }^{49}$ This imbalance leaves the "trustee" - in this case, the patient - vulnerable. ${ }^{50}$ Courts will consider the physicians' traditional duties in light of the fiduciary relationship and recognize direct claims for breach of fiduciary duty. ${ }^{51}$ Because of this special relationship, the scope of the legal duty owed to the patient is greater than it would otherwise be. Requirements of utmost good faith and honesty are imposed on the physician. Conflicts in the physician's duties to the patient, and duties to his employer, or even the broader healthcare system, must be resolved in favor of the patient. Further, the protections that physicians have from liability are limited by their fiduciary status. In turn, the vulnerability of patients limits their obligation to mitigate the harm that may occur to them and their obligation to safeguard their own interests. Indeed, the reliance of patients on the physician limits their agency. ${ }^{52}$ This may affect how courts consider remoteness of the injury in time and possible lack of foreseeability and whether delays in bringing an action are relevant. ${ }^{53}$

\section{Implications for genetics and genomics}

The fiduciary nature of the physician-patient relationship may have particular relevance for attempts by physicians to transfer responsibility for genetic recontact to patients (see below). Even where patients fail to take measures to remain informed of their genetic risks and to identify and address their genetic risks, courts may still place responsibility on physicians for failing to communicate a patient's genetic risk, because of the reduced autonomy of the patient. This recognizes that patients could assume that their doctor is remaining vigilant to their genetic wellbeing, and that the geneticist would take measures to contact them if a change in the meaning of their genetic information arose. ${ }^{54}$ Further, the obligation of utmost good faith ${ }^{55}$ indicates that costreduction directives from hospitals in diagnostic and treatment cannot justify a reduction in standard 
Draft Submission- Health Law in Canada (June 2019) - Publication Pending Final Review

of care. The significant associated costs of genetic testing, care, reanalysis and recontact cannot alone justify the physician's limited provision of such care. ${ }^{56}$

\section{THE TRADITIONAL DUTIES OF PHYSICIANS IN GENETICS}

The primary element on which the question of liability turns is whether the physician breached "the standard of care of a physician in similar circumstances"? ${ }^{57}$ In other words: "Did the physician breach a legal duty towards the patient?" In this section, we review traditional physician duties potentially relevant to genetic recontact. These include: the duty to diagnose, ${ }^{58}$ to inform, ${ }^{59}$ and to provide medical follow-up ${ }^{60}$ (or to instruct) ${ }^{61}$ Each traditional duty is a widely recognized element of the standard of care, ${ }^{62}$ albeit subject to some overlap and divergent interpretations. For each duty, we ask if Canadian courts are likely to interpret it to encompass a duty of genetic recontact. We therefore focus on cases involving duties to communicate risk information and duties that endure over extended periods of time.

\section{A. The duty to diagnose / treat}

Genetic testing is often intimately linked to diagnosing patients. In the case of highly penetrant Mendelian mutations, a genetic interpretation may be tantamount to a diagnosis. The duty of the physician to diagnose includes obligations to exercise due care in performing diagnosis, and to re-diagnose at a later point in time under certain circumstances. ${ }^{63}$ Misdiagnosis does not necessarily amount to negligence; rather, it is suggestive of negligence where: "the physician failed to resort to whatever reasonable tests, equipment or assistance were available."64 The determining factors in performing a diagnosis is not the correctness of the result, or even how close the result was to the true diagnosis. Rather, it is whether the correct methodology was employed with regard to testing, equipment, ${ }^{65}$ third-party expertise,${ }^{66}$ and the proper procedure of differential diagnosis.${ }^{67}$ Observation of appropriate principles and procedures is critical to discharging the duty to diagnose. ${ }^{68}$ 
Draft Submission- Health Law in Canada (June 2019) - Publication Pending Final Review

Consideration of the patient's medical history and relevant health records is also required in prudent diagnosis. ${ }^{69}$ The duty to diagnose becomes a duty to refer where the physician does not have the expertise to handle the diagnosis. ${ }^{70}$

In Ross Estate v Hiscock, the court held that the physician had a general obligation to inquire as to the family history of patients in regard to heritable diseases. If the patient discloses a family history of inheritable illness, the physician should account for it in deciding whether to make a differential diagnosis. ${ }^{71}$ The physician is not required to independently confirm the information provided. ${ }^{72}$ The duty to diagnose can also encompass a duty to order a molecular genetic test. ${ }^{73}$ Physicians without specialized genetic knowledge could be obligated to refer patients to genetic counseling where they appreciate the potential for genetic risk to their patients, but do not possess specialized genetic training. ${ }^{74}$

A duty to re-diagnose at a later point in time can arise where the condition does not respond to treatment. ${ }^{75}$ Adverse change in the symptoms of the patient suggestive of an incorrect initial diagnosis can also trigger the duty. ${ }^{76}$ The physician must generally remain vigilant to the signs of a potential misdiagnosis; the obligation to actively reconsider diagnosis is heightened ${ }^{77}$ by the discovery of 'red flags' such as new symptoms, persistent symptoms, or new information that cast doubt on the original diagnosis. ${ }^{78}$ Limited case law asserts an obligation to reassess a diagnosis continually over the course of treatment. ${ }^{79}$

The legal duty to re-diagnose is unlikely to encompass genetic recontact for the following reasons. First, a physician can only observe persistent or worsening symptoms within the context of ongoing treatment. A duty to re-diagnose can therefore only apply to current patients. Second, a change in meaning of genetic test results is not clearly analogous to a deterioration of manifest symptoms. An update in professional guidelines may be more analogous. Third, most misdiagnosis 
Draft Submission- Health Law in Canada (June 2019) - Publication Pending Final Review

case law is concerned with the physician's choice of procedure and tests in discharging an uncontested obligation to diagnose, rather than a failure to attempt diagnosis. The crux of the failed analogy is this: while physicians are able to observe manifest symptoms in the course of ongoing treatment, they are unlikely to encounter updated genetic interpretations. In rare cases, this may occur serendipitously where another patient (e.g., a family member) with a similar mutation is tested. Recognition of such a duty, however, would do little to address the broader public health dilemma of the changing meaning of genetic data. As we argue below, this dilemma can only be meaningfully addressed through adaptive healthcare and HIT systems.

\section{B. The duty to inform}

Recontacting patients with updated genetic results is essentially about informing patients of updated risk information. The traditional duty of physicians to inform therefore forms a central part of our analysis. In particular, we consider obligations of physicians to disclose new risk information over time.

The duty to obtain consent to treatment has evolved into a duty to obtain informed consent. ${ }^{80}$ Prior to treatment, physicians must disclose the material, special and unusual risks a reasonable person in the patient's position would want to know. ${ }^{81}$ In common law Canada, the standard for informed consent is determined by the patient's reasonable expectation of disclosure. ${ }^{82}$ Civil law cases have rejected this "reasonable patient" test and have adopted a rational subjectivity test, which requires the physician to act reasonably while evaluating each situation on a case-by-case basis. This would also include taking into account the patient's particular situation. ${ }^{83}$

This duty has since expanded to a post-treatment duty to disclose where the patient has questions about the procedure,${ }^{84}$ a medical error occurs,${ }^{85}$ or a new risk is discovered posttreatment. ${ }^{86}$ In Toth, the court held that the physician's possession of health-critical information 
Draft Submission- Health Law in Canada (June 2019) - Publication Pending Final Review

created a duty to disclose ${ }^{87}$ Courts in Canada ${ }^{88}$ and the United States ${ }^{89}$ have modified the general requirement that a continuing physician-patient relationship exist in assessing the duty to disclose; the test is instead whether the physician was responsible for the care to which the information pertains. Consequently, the duty to disclose may arise even when a physician has no continuing ties to the patient. The duty to disclose may be fiduciary in nature (see above) and has sometimes been interpreted as broadly as a general obligation of honesty and disclosure. ${ }^{90}$ Post-treatment disclosures are to be made expediently, as soon as the physician becomes aware of the undisclosed error or risk. ${ }^{91}$ Specialists and hospitals can discharge the duty to disclose by providing timely information to the patient's family doctor sufficient for the family doctor to make the required disclosure. ${ }^{92}$

The interpretation of the physician's duty to disclose may be informed by the manufacturer's “duty to warn." In Rivtow Marine v Washington Iron Works, the Supreme Court of Canada held that knowledge of the danger associated with the use of a product discovered after distribution on the part of both the manufacturer and the distributor made them liable for non-disclosure: "knowledge of the danger... carried with it a duty to warn." 93 Courts have not made clear whether continuing disclosure requirements are assessed from the perspective of the patient (like informed consent), ${ }^{94}$ or the reasonable physician. ${ }^{95}$ Regardless, plaintiffs must also establish causation. The causal test in most of Canada is as follows: where a physician fails to disclose a risk, the plaintiff will only be able to recover if a prudent patient in their position would have acted on the information to limit the injury suffered. ${ }^{96}$ In Quebec's civil law, courts instead assess whether the particular patient would have subjectively chosen to act on the information; in the absence of evidence to that effect, the court will then consider what a reasonable person in the patient's position would have done. ${ }^{97}$

\section{Implications for genetics and genomics}


Draft Submission- Health Law in Canada (June 2019) - Publication Pending Final Review

The duty to disclose would seem to be the most promising basis supporting a duty of genetic recontact. A change in the interpretation of a genetic test result is comparable to the discovery of a new adverse drug effect, or medical device defect. The duty to disclose may also extend to former patients of physicians, as long as the physician was involved in the initial testing. But a plaintiff faces several major practical barriers in genetics. First, physicians are unlikely to become aware of genetic reinterpretations. Genetic interpretations are not (yet) subject to the same systematic surveillance and reporting as adverse drug events. Physicians do not have a duty to hunt for new genetic meanings, or to routinely reanalyze the patient's genetic information. ${ }^{98}$ Moreover, the clinical significance of reinterpretations is often unclear. Second, establishing a legal relationship with former patients may be harder when the risk arises from the individual's genetic make-up and not from a drug or device administered by the physician. Third, establishing causation is always difficult in genetics because genetic risks may materialize regardless of the disclosure, and patient choices to act on genetic results are often subjective. Causation would be even harder to establish where long periods of time have passed before reinterpretation. The window for intervening or withholding intervention may have closed. A number of these difficulties are demonstrated by the South Carolina lawsuit Athena $v$ Williams. ${ }^{99}$ In that case, a plaintiff alleges that a genetics laboratory misinterpreted a genetic test result, resulting in a child's inappropriate drug treatment and death. It is also alleged that the laboratory failed to update the patient in a timely manner when that laboratory discovered the variant misclassification. The case reflects the uncertainty over the standard for variant interpretation or reinterpretation, and other causation issues: "Would the new result have changed treatment? Would the change in treatment have prevented the outcome?"100

Genomics raises the additional challenge of determining what subset of the millions of individual variants (e.g., results, secondary findings) would potentially be the subject of recontact. It is also unclear if the subjective elements of the modern informed consent doctrine would apply to 
Draft Submission- Health Law in Canada (June 2019) - Publication Pending Final Review

duty to disclose. First, absent ongoing patient interactions, physicians would have little current information about the patient's specific circumstances. Second, it rapidly becomes impractical to incorporate subjective considerations as the number of variants subject to an ongoing duty to disclose expands across the genome. We now turn to the duty to follow-up, which can provide insights into the appropriate division of responsibility between physician and patient.

\section{The duty to follow-up}

The physician's duty to provide follow-up care has received widespread recognition in Quebec's civil law. ${ }^{101}$ Common law Canada has also recognized this duty, ${ }^{102}$ though the 'duty to treat' ${ }^{103}$ postoperatively and the 'duty to instruct' ${ }^{104}$ (discussed below) overlap with its constituent obligations. The scope of the physician's duty to follow-up has expanded in light of the increasing specialization and decentralization of medical practice. ${ }^{105}$ The duty to 'follow-up' includes an obligation to contact the patient to ensure continuity of care. This obligation can arise on receipt of test results, ${ }^{106}$ if the patient has not attended a scheduled follow-up appointment concerning important care, ${ }^{107}$ or if the patient has disregarded the physician's instructions. ${ }^{108}$ It requires the physician to inform the patient of scheduled follow-up care. ${ }^{109}$ The obligation is limited in nature; the need to ensure attendance of follow-up appointments despite patient non-compliance is restricted if the care is routine or otherwise not health-critical. ${ }^{110}$ Where follow-up care is critical to the health of the patient, it is not sufficient to attempt to contact the patient; proof that the notice has reached the patient is required. ${ }^{111}$ The duty to follow-up also includes an obligation to monitor medical conditions actively where appropriate, ${ }^{112}$ to act on readily available information about a patient's condition (such as diagnostic results), ${ }^{113}$ and to take measures to refine an indeterminate diagnosis. ${ }^{114}$ These obligations are generally limited to health-critical circumstances ${ }^{115}$ or the post-operative context. $^{116}$ 
Draft Submission- Health Law in Canada (June 2019) - Publication Pending Final Review

Discharging the obligation to follow-up can require the use of an information management system. If the physician fails to follow-up despite the use of a system, negligence is determined first with respect to the adequacy of the system, ${ }^{117}$ and second regarding the use thereof. The appropriateness of a system is not a question of medical judgment but is subject to the appreciation of the courts, ${ }^{118}$ consequently, it is possible for a court to hold reliance on an inappropriate follow-up system negligent even if it is an accepted standard of practice in medicine. ${ }^{119}$ A physician who fails to follow-up despite the system functioning according to its design can be held negligent, if the design of the system enabled the need for follow-up to fall through the cracks, ${ }^{120}$ or if the system fails to operationalize follow-up despite the physician's office receiving results that mandate follow-up. ${ }^{121}$ Reliance on an appropriate institutional follow-up system eliminates the obligation to create a personal follow-up system; ${ }^{122}$ if the institution where the physician works does not have a follow-up system, she is obligated to implement her own. ${ }^{123}$

The duty to follow-up may be complemented or delimited by a duty to instruct the patient to take steps in furtherance of their treatment. ${ }^{124}$ This duty requires not only that correct instruction be conveyed, but also that the patient understand the medical significance of the instruction. ${ }^{125}$ The communication of the instruction must be unambiguous. ${ }^{126}$ It is necessary to convey the risk associated with non-performance. ${ }^{127}$ The obligation to instruct can arise not only in ensuring proper treatment, but also in mitigating its risks. ${ }^{128}$ This can include an appreciation of which risks are most relevant to the particular patient. In Joshi v Woolley, the incompatibility of a specific patient's wellbeing with pregnancy ${ }^{129}$ heightened the physician's obligation to instruct her on how to mitigate the minute risk of her tubal ligation failing. Last, the instructions must be clear enough that the patient can follow them. ${ }^{130}$ Instruction informs patients as to their duties and sets their boundaries. 
Draft Submission- Health Law in Canada (June 2019) - Publication Pending Final Review

Consequently, a physician by way of instruction can transfer responsibilities that would otherwise fall to them to the patient, where reasonable. ${ }^{131}$

\section{Implications for genetics and genomics}

The physician's obligation to follow-up is generally restricted to the return of test results, the communication of post-treatment instructions, post-operative care and post-treatment monitoring. It ensures continued oversight of lingering ill-health and of the deleterious effects of treatments surgical and other. This duty is unlikely to found a general obligation to reanalyze the genetic results of a patient, to recontact them to update variant classifications, and to suggest re-testing upon the emergence of new testing methods, testing policies, or updated genetic meanings. ${ }^{132}$ These concern the latent emergence of medical risk not anticipated on initial diagnosis and treatment, while followup concerns the ongoing management of risks and injuries inherent to the initial diagnosis and treatment. Cases where physicians are provided with updated information, such as by a zealous lab technician or subsequent testing of a family member, would be more appropriately dealt with under a duty to disclose. In genetics, the information is the intervention. This blurs concepts of consent, risk disclosure, follow-up, and instruction, especially for VUS. ${ }^{133}$

At first glance, the duty to establish safe information handling systems appears to support a duty of genetic recontact. It is not outlandish to imagine clinical decision support tools that could provide physicians with updates when variant classifications change. If such tools became reliable and convenient, it could be considered "unsafe" not to adopt them. Importantly, this could become a legal standard, even if such systems are not commonly adopted by medical practitioners. Adoption of these systems may be subject to legal appreciation of the standard of care, and courts may choose not to defer to medical discretion. 
Draft Submission- Health Law in Canada (June 2019) - Publication Pending Final Review

In genetics, are physicians required to instruct patients that the meaning of their result may change over time? On one hand, this would respect patient autonomy and share responsibility with patients for recontact. On the other hand, this could add additional confusion and complexity to the reporting of genetic test results and undermine patient motivation to act on those results. Essentially, this would entail instructing patients to be skeptical of the meaning of their test results, which may cut against the tests' effectiveness. Physicians also tend to have limited time, let alone training, to explain this complexity. ${ }^{134}$ Should physicians instruct patients that they are responsible to initiate recontact in the future, in case the meaning of their result changes or new testing methods emerge? This exculpatory approach is favored by the US ACMG guidelines. ${ }^{135}$ While this may limit malpractice risks, it is unlikely to improve patient care. The findings of Kausmeyer ${ }^{136}$ et al. and Griffin ${ }^{137}$ et al. suggest, however, that the majority of patients assume recontact to be the responsibility of the genetic service provider (geneticist or laboratory). Regardless, it seems prudent to explain to patients the scope of anticipated recontact and the kinds of genetic information that will trigger recontact, as well as how the patient should go about receiving updated information absent physician-initiated recontact, especially as practices concerning recontact may be different from institution to institution, within a single jurisdiction or healthcare system. ${ }^{138}$

\section{The duty of confidentiality}

Debates over exceptions to the traditional duty of confidentiality suggest that physicians can owe duties to disclose genetic risk information to third parties. An exception to confidentiality is the professional's duty to warn an identifiable third party of a clear, serious and imminent danger. ${ }^{139}$ The familial nature of genetics raises the question of whether or not physicians have a duty to disclose genetic risk information to patients' relatives. In Watters $v$ White, the Quebec Court of Appeals found that physicians have no duty to inform patients' relatives, in part because of the difficulty with 
Draft Submission- Health Law in Canada (June 2019) - Publication Pending Final Review

genetic risk information of satisfying the "imminence" criteria of the duty to warn confidentiality exception. $^{140}$

In $A B C v$ St George's, a UK appeal court has allowed a case struck out by a lower court to proceed to trial, which will consider if a physician had a duty to warn a patient's pregnant daughter of a $50 \%$ risk of inheriting Huntington's disease. ${ }^{141}$ The physician had respected the patient's refusal to disclose so as not to cause distress to his daughter or trigger an abortion. The appeal court concluded that non-disclosure of a genetic risk can create a reasonably foreseeable harm, and that there the relationship between the doctor and patient's offspring was sufficiently close to support a duty of care (i.e., proximity). ${ }^{142}$ Neither party contested these findings. The case was remitted to trial court to determine if there is public policy not to recognize this duty of care ${ }^{143}$ and if the facts should give rise to liability. ${ }^{144}$ If both the duty to warn family members and the duty to re-contact patients of genetic result changes are recognized, the two emerging duties could potentially intersect. Given the familial nature of genetic risks, could there also be a duty to warn family members of re-interpreted results?

\section{RECENT TRENDS IN PROFESSIONAL GUIDELINES}

A series of professional guidelines have been released, offering some contradictory pronouncements on the duty to recontact. The American College of Medical Genetics and Genomics (ACMG)'s 2019 policy statement frames the duty to recontact as a shared responsibility across patients and various other genetic care providers. The ACMG guidelines envision a limited obligation to make reasonable efforts to return results to appropriate parties, such as patients and other more proximate healthcare providers, ${ }^{145}$ incumbent on all actors in possession of relevant new information. The primary care physician has a limited responsibility to attempt to recontact patients upon receiving notice of a reinterpretation from a laboratory. However, it encourages physicians to adopt exculpatory language during consent and pre- and post- test counselling, to ensure that the 
Draft Submission- Health Law in Canada (June 2019) - Publication Pending Final Review

ultimate responsibility for requesting recontact falls on the shoulders of the patient. The patient is further charged with ensuring healthcare providers are given updated contact information necessary to perform recontact. ${ }^{146}$ Is it realistic to expect patients to deal with the changing meaning of genetic information? Could a caveat that results may change confuse patients and discourage them from acting on their initial result?

The American Society of Human Genetics (ASHG) position statement is addressed to researchers. ${ }^{147}$ It recognizes a limited duty to recontact. The duty arises when an individual result, already returned to a participant, which pertains to the study's area of research is subject to a reinterpretation that is expected to affect the participant's medical management. ${ }^{147}$ Recontact is advised but not required where new meaning is discovered as regards pathogenicity, but the new information has no implications for the medical management of the participant. ${ }^{148}$ The anticipated timeframe for recontact is six months from discovering that the participant's results have been reinterpreted. ${ }^{149}$ These broad obligations are circumscribed by a number of limiting factors such as the practicability of performing recontact, ${ }^{150}$ the availability and time limits on the research funds, ${ }^{151}$ and the patient's consent to recontact or return of results, among others. ${ }^{152}$ The ASHG guidance highlights the Janus-faced nature of the obligation to recontact: limited where technological barriers arise, potentially onerous where technology enables it. The ASHG guidelines place special emphasis on the potential for a stricter obligation to arise where information technologies, automation, databases and other "dedicated institutional mechanisms" make reasonable the discharge thereof. ${ }^{153}$

The contrast between the ACMG and ASHG guidelines challenges the traditional paradigm that clinical ethics impose stricter duties toward patients than research ethics toward participants. ${ }^{154}$ Professional codes can be aspirational without necessarily risking expanded liability, though they can inform a court's determination of the standard of care at a given time. Discrepancy between professionals' ethical duties and their legal obligations can be beneficial. A high ethical burden can 
Draft Submission- Health Law in Canada (June 2019) - Publication Pending Final Review

guide physicians' behavior and ensure improved clinical outcomes for patients, while a more lenient legal standard can insulate the exercise of professional discretion from liability.

Practitioners should be mindful that while medical ethics and professional regulations can inspire judge-made legal standards, these remain far from analogous. ${ }^{155}$ Courts may consider professional codes as evidence of an accepted professional standard. They have received favorable treatment in courtrooms where supported by corroborating expert testimony, ${ }^{156}$ or secondary evidence shows they reflect actual medical practice. ${ }^{157}$ As ethical codes on recontact become uniform and a consensus emerges as to their content, genetic professionals may be able to rely on them as proof of their compliance with law. So long as competing standards remain, genetic professionals should be mindful that adherence to a professional standard will not necessarily preclude liability. Pronounced differences in the 2019 ACMG and ASHG guidelines show that contemporary medical ethics literature on recontact is discursive rather than descriptive. Consequently, courts are not likely to grant such guidance significant value as evidence that there is a legal duty of genetic recontact (or not).

\section{SUMMARY}

We find no clear legal precedent in Canada currently supporting a general legal duty to recontact in genetics. This conclusion echoes the findings of recent scholarship and professional society positions in the US ${ }^{158}$ and Europe. ${ }^{159}$ The Canadian case law does appear to support a duty to recontact in specific circumstances. As Clayton et al. have argued in the context of a potential obligation to return incidental findings, given the current impracticality of a general duty to recontact, "the standard of care will be defined almost entirely by the results that are 'pushed' to them by genetic laboratories." ${ }^{160}$ In other words, only if updated genetic information from which clear clinical significance can be inferred is readily made available to physicians will they be likely to have a duty to disclose. This is the key consideration for policy makers and professional 
Draft Submission- Health Law in Canada (June 2019) - Publication Pending Final Review

associations contemplating guidelines. Without systems in place to identify and push useful genetic reinterpretations to physicians, a duty to recontact is likely to achieve very little (and may in fact have significant unintended consequences in terms of discouraging genetic testing in the first place). Individual responsibility is not the solution to a systemic problem. We return to this in our discussion.

Absent a clear precedent or systemic revolution in physician practice, Canadian courts will remain unlikely to recognize novel legal duties in genetics. This was clearly demonstrated in Watters $v$ White, where the Quebec Court of Appeal held that it was inappropriate to obligate physicians to disclose genetic risk to the relatives of patients, in part because:

"The social costs of such a duty could prove to be prohibitive. It could serve as a disincentive to undertake medical work in fields where genetic risks are present. Moreover, the duty to warn as announced by the judge could transform the doctor-patient relationship as it is currently understood." 161

Similar policy reasons will likely restrain courts from imposing a duty to recontact. Policy arguments for a duty to recontact continue to be based on unproven assumptions that recontact is necessarily good for patients, that genetic reinterpretations will often be clear and useful, that the physicianpatient relationship is "lineal and eternal", and that primary care physicians are genetically literate. ${ }^{162}$

Recognition of a duty to recontact could also have important unintended consequences if courts simultaneously recognize other novel duties in genetics. A duty to return secondary or incidental findings from whole-genome sequencing would in turn mean a duty to recontact across numerous variants. A duty to warn family members of genetic risks would also mean a duty to recontact family members (although a duty to warn family members could alternatively be conceived as a substitute for a duty to recontact in cases where the family members' result is found to be 
Draft Submission- Health Law in Canada (June 2019) - Publication Pending Final Review

outdated). Finally, even if a plaintiff were to establish that a physician breached a duty to recontact, proving causation in the genetics context is a challenge, and may be more so where years pass before the duty even emerges.

Regardless of whether or not recontact is a legal duty, physicians seeking to do so may confront unresolved questions on how to recontact patients. ${ }^{163}$ The operationalization of recontact will necessarily require the use of policies and protocols supported by technological infrastructures enabling their coherent functioning. Who will assess the usefulness of reinterpretations, and according to what standards or criteria? What steps will be taken to keep patient contact information up to date or locate them? How can physicians effectively communicate important risk information, especially when they are essentially cold-calling patients? And what if the patient is not interested in receiving updated genetic information?

\section{DISCUSSION: The impact of genomic and health information technologies}

Querulous debate as to whether the physician should, from a liability perspective, bear the responsibility for genetic recontact and reinterpretation belies a more critical question: Is the physician capable of assuming and discharging an obligation, given the infrastructures to which she has access? Patients want to consult up-to-date genetic information. Such a responsibility cannot be discharged by expecting physicians to fulfill onerous new responsibilities that do not cohere with their traditional duties. Tort law is an unwieldy tool for effecting a considerable change in the praxis of genetic care. Rather, it falls to healthcare institutions or systems to unlock the potential of the accurate information at their disposal, disseminate it to health practitioners and automatically update patients and practitioners.

A duty to recontact would be ethically justified if the health benefits of new medical information outweigh the risks and burdens of return. Health information technologies (HIT) affect 
Draft Submission- Health Law in Canada (June 2019) - Publication Pending Final Review

this balance by drastically lowering the burdens. They enable new lines of communication between healthcare professionals and institutions and their patients. ${ }^{164}$ When new medical information emerges - e.g., adverse drug reactions, medical device defects, or the release of new tests, treatments, or preventative interventions - affected patients can be automatically identified through electronic health records. Family physicians and their patients can then be contacted directly by email, patient portal, or mobile device.

Technologies enabling routine recontact and reanalysis are already being developed and implemented in genetic laboratories and other healthcare contexts. The role of genetics laboratories in clinical genetics is also changing. Rather than simply processing diagnostic requests, laboratories are starting to serve as repositories of genetic information and to coordinate care. They are wellplaced to do this as they have access to patient information, have points of contact with clinicians and physicians, and frequently perform updated analysis of analogous genetic information for different patients. In the United States, Emory Laboratories created two platforms, EmBase, which "tracks changes in variant classifications, generating notifications for the laboratory about which cases predate a reclassification and are, therefore, in need of a review and possible report update" and "EmVClass, a web-based tool that allows any user to access ... [a] variant's current classification.” ${ }^{165}$ The former can be used to transfer data to patients' electronic records and thus communicate genetic reinterpretation to clinicians. ${ }^{166}$ The latter allows for direct patient consultation of genetic information; as the variants must be consulted individually, ${ }^{167}$ this is only useful to those patients with particular variants of concern (ex. VUS or pathological variants of note), rather than those whose assumed non-clinically significant variants are later reinterpreted as pathological. ${ }^{168}$ The Partners HealthCare Center for Personalized Genetic Medicine's Laboratory for Molecular Medicine has created an application called GeneInsight Lab that alerts the healthcare professional when new 
Draft Submission- Health Law in Canada (June 2019) - Publication Pending Final Review

clinically significant information is learned about a variant identified in one of their patients, ranked "high," "medium," or "low" priority. ${ }^{169}$

In the United Kingdom, clinical genetic registers compile patient information for various purposes. These include research, family follow-up and, for upwards of eighty percent of registers surveyed in 2000, recontact for clinically significant reinterpretations and newly available screening methods. ${ }^{170}$ These registers can be general or disease-specific; general registers have been lauded as improving coordination of care, preventing duplication of efforts, and limiting costs. ${ }^{171}$ The increasing centralization of genetic and genomic data repositories in the research ${ }^{172}$ and clinical $^{173}$ contexts will further physicians' ease of access to reinterpreted genetic results. Computer-aided genetic registers intended for the identification and contact of persons at risk of genetic disease have been used in the United Kingdom and other European countries since the 1970s. ${ }^{174}$

The emergence of new technologies in genetic practice illustrates the potential for a "learning healthcare system," 175 enabling the "rapid progression of knowledge from the lab bench to the bedside." ${ }^{176}$ Just as commercial service providers use data for purposes synergistic with the initial intended use, ${ }^{177}$ the healthcare system must "[maximize] use of its internal data and resultant information" 178 in the interest of its patients. Institutional actors, such as hospitals and laboratories, must ensure that the medical knowledge generated is made accessible to patients that most need it and the health professionals responsible for their care. This includes patient information such as screening and testing results, research results such as the availability of new testing and screening methods, and new interpretations of genetic information.

Patients are seeking such a "learning healthcare system," which marshals big data, machine learning technologies, and artificial intelligence (AI) in the interest of medical service recipients. Medicine generally would benefit from these technologies, but successful genetic and genomic 
Draft Submission- Health Law in Canada (June 2019) - Publication Pending Final Review

practice will require them; the volume of information to be reanalyzed and temporal scope of requisite recontact are not otherwise navigable. This is no techno-utopianism, but the continuation of a rallying call ${ }^{179}$ for medical practice to conform to standards met in the insurance, ${ }^{180}$ financial services, ${ }^{181}$ consumer,${ }^{182}$ and automotive sectors. ${ }^{183}$ In a learning healthcare system, relevant research and clinical findings will be brought to the attention of physicians through a shared network coordinating public, private, and international institutions. Practitioners faced with rare clinical findings and case-specific ethical challenges can parse the whole of clinical practice for other similar instances, both as regards their medical and ethical components. Evolving best practices for recontact and reanalysis can be defined and refined through reliance on such a system. ${ }^{184}$ The speed at which knowledge of genomics advances ${ }^{185}$ and the contextual nature of legal and ethical decision-making regarding recontact make a learning healthcare system relevant to the establishment of coherent standards of care in genetic practice. There is already empirical evidence supporting clinical benefits from periodic reanalysis of whole-genome sequence data and recommendations for periodic reanalysis. ${ }^{186}$

Practical considerations for recontact systems include the following questions: "What constitutes a threshold for medical significance? What are the burdens of returning, e.g., is there a danger of information overload for practitioners and patients? ${ }^{187}$ Who will be considered an affected patient?" A current patient test or time-limit could be established to avoid duplicative reporting when individuals have moved on to new providers. ${ }^{188}$ Who should be recontacted - the specialist, primary care physician or the patient? This brings us full circle to questions of coordination and individual professional responsibility. A learning healthcare system will strive to continuously improve patient care by providing infrastructure and coordination that facilitates the role of physicians in recontact, rather than simply imposing the problem on a single actor. 
Draft Submission- Health Law in Canada (June 2019) - Publication Pending Final Review

\section{CONCLUSION}

Yuval Noah Harari highlights that the true potential of AI and networked medicine are updateability and connectivity:

"Two particularly important nonhuman abilities that AI possesses are connectivity and updatability. ... it is easy to integrate [computers] into a single flexible network ... if the World Health Organization identifies a new disease, or if a laboratory produces a new medicine, it is almost impossible to update all the human doctors in the world about these developments. In contrast, even if you have ten billion AI doctors in the world - each monitoring the health of a single human being - you can still update all of them within a split second, and they can all communicate to each other their feedback on the new disease or medicine."189

Using AI technologies to ensure uninterrupted healthcare across unprecedented temporal, geographic and informational boundaries is not only imaginable - it reflects current practice in client service across many economic sectors, and it has started to be integrated to general and genomic healthcare initiatives. Significant HIT infrastructure and AI is necessary to unlock the medical potential of rich genomic information. A coordinated effort by actors across the healthcare, research, and governance communities will be necessary to transform whole genome sequencing from an expensive and indeterminate predictive tool to a reliable and adaptive platform informing whole-life care. 
${ }^{1}$ Gina Kolata, "The Results of Your Genetic Test Are Reassuring. But That Can Change.", The New York Times (16 October 2018), online: <https://www.nytimes.com/2018/10/16/health/genetic-testing-mutations.html>.

${ }^{2}$ Gary E Marchant \& Rachel A Lindor, "Genomic Malpractice: An Emerging Tide or Gentle Ripple." (2018) 73 Food \& Drug LJ 1 at 5 [Marchant \& Lindor, "Genomic Malpractice"].

${ }^{3}$ Gary E Marchant \& Rachel A Lindor, "Personalized medicine and genetic malpractice" (2013) 15:12 Genet Med 921 [Marchant \& Lindor, "Personalized Medicine"].

${ }^{4}$ Marchant \& Lindor, "Genomic Malpractice", supra note 2 at 37.

${ }^{5}$ Ibid at 4.

${ }^{6}$ Ibid at abstract.

${ }^{7}$ Ibid at 6.

${ }^{8}$ For the US, see Mark A Rothstein, "Reconsidering the duty to warn genetically at-risk relatives" (2018) 20:3 Genet Med 285; for Canada, see Ma'n H Zawati \& Adrian Thorogood, "The physician who knew too much: A Comment on Watters v. White" (2014) 21 Health LJ 1; for the UK, see Colin Mitchell et al, "Exploring the potential duty of care in clinical genomics under UK law" (2017) 17:3 Med Law Int'1 158; and Naomi Hawkins \& Timon Hughes-Davies, "Striking a balance: resolving conflicts between the duty of confidentiality and duties to third parties in genetics" (2018) 38:4 Leg Stud 645.

${ }^{9}$ Ellen Wright Clayton et al, "Managing incidental genomic findings: legal obligations of clinicians" (2013) 15:8 Genet Med 624.

${ }^{10}$ Yvonne A Stevens, Grant D Senner \& Gary E Marchant, "Physicians' duty to recontact and update genetic advice" (2017) 14:4 Pers Med 367.

${ }^{11}$ Yvonne Bombard, Kyle B. Brothers et al. "ASHG Position Statement : The Responsibility to Recontact Research Participants after Reinterpretation of Genetic and Genomic Research Results" The American Journal of Human Genetics 104, 578-595, April 4, 2019 at 579.

${ }^{12} \mathrm{Ibid}$ at $584-585$.

${ }^{13}$ Ibid.

${ }^{14}$ Sarah Macklin et al, "Observed frequency and challenges of variant reclassification in a hereditary cancer clinic" (2018) 20:3 Genet Med 346; Jacqueline Mersch et al, "Prevalence of variant reclassification following hereditary cancer genetic testing" (2018) 320:12 JAMA 1266; Scott A Turner et al, "The impact of variant classification on the clinical management of hereditary cancer syndromes" (2018) Genet Med 1; Caroline F Wright et al, "Making new genetic diagnoses with old data: iterative reanalysis and reporting from genome-wide data in 1,133 families with developmental disorders" (2018) 20:10 Genet Med 1216.

${ }^{15}$ Jordan Lerner-Ellis et al, "Canadian Open Genetics Repository (COGR): a unified clinical genomics database as a community resource for standardising and sharing genetic interpretations" (2015) 52:7 J Med Genet 438; ACMG Board of Directors, "Laboratory and clinical genomic data sharing is crucial to improving genetic health care: a position statement of the American College of Medical Genetics and Genomics" (2017) 19:7 Genet Med 721.

${ }^{16}$ Bruce Anderson, Discovery in Legal Decision-making, (Springer 1996).

${ }^{17}$ Institute of Medicine, Roundtable on Value \& Science-Driven Health Care. The Roundtable. Washington, DC; 2012 (A learning healthcare system in one in which "science, informatics, incentives, and culture are aligned for continuous improvement and innovation.")

${ }^{18}$ D. (B.C.), Re. Ontario College of Physicians and Surgeons Discipline Committee; 2014 Carswell Ont 12009 at para 49-51.

${ }^{19}$ Gerald B Robertson \& Ellen I. Picard, Legal Liability of Doctors and Hospitals in Canada, $5^{\text {th }}$ ed (Carswell, 2017) at 8 .

${ }^{20}$ L. (G.) v. College of Physicians \& Surgeons (Alberta) [1994] 3 W.W.R. 277, [1994] A.W.L.D. 112 at para 20 (where a physician was found responsible for professional misconduct for engaging in a sexual relationship with a patient who reasonably thought a professional relationship existed despite the fact that care was not continuing.) ${ }^{21}$ Cook v Abbot (1980) 11 C.C.L.T. 217; 39 N.S.R. (2d) 70 at paras 31-36. Reversed in result (1980) 13 C.C.L.T. 264, 3 A.C.W.S. (2d) 423 but not challenged on this point of law. See also Legal Liability of Doctors and Hospitals in Canada. "Chapter I: The Doctor-Patient Relationship," at 8.

${ }^{22}$ Bombard, Brothers et al. supra note 11.

${ }^{23}$ Danya F Vears, Karine Sénécal \& Pascal Borry, "Reporting practices for variants of uncertain significance from next generation sequencing technologies" (2017) 60:10 Eur J Med Genet 553.

${ }^{24}$ Sarah S Kalia et al, "Recommendations for reporting of secondary findings in clinical exome and genome sequencing, 2016 update (ACMG SF v2.0): a policy statement of the American College of Medical Genetics and 
Genomics" (2017) 19:2 Genet Med 249; Sue Richards et al, "Standards and guidelines for the interpretation of sequence variants: a joint consensus recommendation of the American College of Medical Genetics and Genomics and the Association for Molecular Pathology" (2015) 17:5 Genet Med; Robert C Green et al, "ACMG recommendations for reporting of incidental findings in clinical exome and genome sequencing" (2013) 15:7 Genet Med 565.

${ }^{25}$ Jennifer K Wagner, Jessica T Mozersky \& Reed E Pyeritz, “'Use it or lose it' as an alternative approach to protect genetic privacy in personalized medicine" (2014) 32:2 Urol Oncol 198.

${ }^{26}$ Robertson \& Picard, supra note 19 at 212-215.

${ }^{27} \mathrm{Ibid}$.

${ }^{28}$ Meyer v Gordon (1981), 1981 CarswellBC 1194 [1981] B.C.J. No. 524 at paras 206-207 (BCSC).

${ }^{29} \mathrm{Ibid}$ at para 209.

${ }^{30}$ Robertson \& Picard, supra note 19 at 441.

${ }^{31}$ Ibid.

${ }^{32}$ Nola M Ries, "Innovation in Health Care, Innovation in Law: Does the Law Support Interprofessional Collaboration in Canadian Health Systems?" (2016) 54 Osgoode Hall L.J. 87 at 108-109.

${ }^{33}$ Ibid at 109.

${ }^{34}$ Ibid. See also Preston v Chow, 2007 MBQB 318.

${ }^{35}$ Allen (Next Friend of) v University Hospitals Board, 2002 ABCA 195; [2002] A.W.L.D. 456.

${ }^{36}$ Williams $v$ Wai-Ping, [2005] O.J. No. 1940; 2005 CarswellOnt 1891 at para 26. See also Ries, supra note 32 at 108-109.

${ }^{37}$ Ries, supra note 32 at 108-109. See also Skeels Estate v Iwashkiw, 2006 ABQB 335; [2006] 11 W.W.R. 632 at para 95.

${ }^{38}$ Ries, supra note 32 at $99-106$.

${ }^{39}$ Rupert v Toth, [2006] W.D.F.L. 1815 [2006] O.J. No. 882 at para 47, 64 [Toth] (A specialist initially provided an indeterminate diagnosis concerning a growth. He ordered further tests that revealed a significant risk. The tests were returned to the specialist and to the patient's general practitioner. The general practitioner told the patient of the diagnosis - "inverting papilloma" - but did not understand the risk it posed. The patient therefore did not have the growth removed, and it developed into terminal cancer. The Court held that the defendant specialist had an obligation to inform the patient of the new risks because he had performed the initial diagnosis and treatment, and because the specialist-patient relationship had never been explicitly terminated).

${ }^{40}$ Pittman Estate v Bain, [1994] O.J. No. 463, 112 D.L.R. (4th) 257 at para 558 [Bain].

${ }^{41}$ Not to mention genetic databases Adrian Thorogood, Robert Cook-Deegan \& Bartha Maria Knoppers, "Public Variant Databases: Liability?" (2017) 19:7 Genet Med 838.

${ }^{42}$ Bombard, Brothers et al. supra note 11 at 580; referring to: Carrieri, Dheensa et al. "Recontacting in clinical practice: an investigation of the views of healthcare professionals and clinical scientists in the United Kingdom" European Journal of Human Genetics volume 25, pages 275-279 (2017).

${ }^{43}$ Ibid.

${ }^{44}$ Carrieri, Jackson et al. "Recontacting patients in clinical genetics services: recommendations of the European Society of Human Genetics" (2018). Draft manuscript version 28 March 2018 at 13-14.

${ }^{45}$ Bombard, Brothers et al. supra note 11 at 581.

${ }^{46}$ Karen L David et al, "Patient re-contact after revision of genomic test results: points to consider-a statement of the American College of Medical Genetics and Genomics (ACMG)" Genetics in Medicine 21, 769-771 (2019).

${ }^{47}$ Ibid.

${ }^{48}$ Norberg $v$ Wynrib 1992 CarswellBC 155; [1992] 2 S.C.R. 226 at para 64-65 [Norberg].

${ }^{49}$ Frame v Smith, 1987 CarswellOnt 347; [1987] 2 S.C.R. 99 at para 67.

${ }^{50} \mathrm{Ibid}$ at paras 39-43.

${ }^{51}$ Barker v Barker, 2017 ONSC 3397139 O.R. (3d) 96. 2017 at paras 115-118 [Barker].

${ }_{52}^{52}$ Norberg, supra note 48 at para 95.

${ }^{53}$ Robertson \& Picard, supra note 19 at 6-7.

${ }^{54}$ Dana T Kausmeyer et al. "A Survey of Patients' Experiences with the Cancer Genetic Counseling Process: Recommendations for Cancer Genetics Programs" (2006) 15:6 Journal of Genetic Counseling 409. Constance A Griffen et al. "Patient Preferences Regarding Recontact by Cancer Genetics Clinicians" (2007) 6:3 Familial Cancer 265 .

${ }^{55}$ Barker, supra note 51 at paras 67, 126.

${ }^{56}$ Law Estate v Simice, [1994] B.C.W.L.D. 1424; [1994] B.C.J. No. 979 at para 28. See also: Robertson \& Picard, supra note 19 at 251-255. 
${ }^{57}$ Brough v Yipp, 2016 ABQB 559; [2016] A.W.L.D. 4878 at para 121.

58 Ibid at paras 116-21.

${ }^{59}$ Ibid.

${ }^{60}$ Philips-Nootens, Suzanne et al., Éléments de la responsabilité civile médicale, $4^{i e ̀ m e}$ Édition (2016 : Cowansville, Québec : Éditions Y. Blais) at 341.

${ }^{61}$ Robertson \& Picard, supra note 19 at 442.

${ }^{62}$ Robertson \& Picard, supra note 19 at 372.

${ }^{63}$ Brough v Yipp, supra note 57 at para 126-9.

${ }^{64}$ Rose v Dujon, 1990 CarswellAlta 464, [1990] A.W.L.D. 683 at paras 103-104.

${ }^{65}$ Ibid.

${ }^{66}$ MacDonald v York County Hospital, [1976] 2 S.C.R, 1976 CarswellOnt 406F at para 17 [MacDonald].

${ }^{67}$ Paniccia Estate v. Toal 2011 ABQB 3262011 CarswellAlta 1372 at paras 37-39, 92. See also Bergen v Sturgeon General Hospital, 1984 CarswellAlta 397; [1984] A.W.L.D. 203 [Bergen].

${ }^{68}$ Robertson \& Picard, supra note 19 at 384-385, 389-391.

${ }^{69}$ Layden v Cope, 1984 CarswellAlta 39652 A.R. 70 at para 22.

${ }^{70}$ MacDonald, supra note 66

${ }^{71}$ Ross Estate v Hiscock 2007 NLCA 2, 262 Nfld. \& P.E.I.R. 343 at paras 39, 41.

${ }^{72}$ Ibid.

${ }^{73}$ Cleveland (Litigation Guardian of) v Hamilton Health Sciences Corp., 2009 CarswellOnt 7853; 183 A.C.W.S. (3d) 574 at paras 42-58, affirmed by the Ontario Court of Appeal: 2011 ONCA 244; [2011] O.J. No. 1401.

${ }^{74}$ Raina $v$ Shaw 2006 BCSC 832; [2006] B.C.W.L.D. 4863 at para 30. See also Bosard v Davey 2005 MBQB 80, [2005] M.J. No. 85 at paras 74-80.

${ }^{75}$ Bergen, supra note 67 at para 17. See also Williams (Litigation Guardian of) v Bowler, [2005] O.J. No. 3323 ; 141

A.C.W.S. (3d) 1056 at paras 243-247; Thomas v Port Colborne General Hospital 1982 CarswellOnt 2622; [1982] O.J. No. 559 at para 15 and preceding.

${ }^{76}$ Gemoto v Calgary Regional Health Authority 2006 ABQB 740; 2006 CarswellAlta 1315 at paras 55, 260-262, 292 [Gemoto], see also Layden v Cope 1984 CarswellAlta 396, [1984] A.W.L.D. 317 at para 26.

${ }^{77}$ Layden v Cope 1984 CarswellAlta 396; [1984] A.W.L.D. 317 at para 26.

${ }^{78}$ In Bergen, supra note 67, the Court held that failure to reconsider an erroneous diagnosis of appendicitis as pelvic inflammatory disease was negligent as the physicians settled on a diagnosis without ruling out more serious ailments first (differential diagnosis), despite the ease of testing for appendicitis and concordance of the patient's symptoms therewith. This was held to be negligent for failure to "reassess [the] patient constantly," to employ proper tests and methodology. It was a culmination of numerous errors in medical judgment (paras 24-33). In Gemoto, supra note 76, "failing to see the signs" of non-improvement was held negligent; in this instance the signs of misdiagnosis created a duty to re-diagnose which was not discharged.

${ }^{79}$ Bergen, supra note 67 at para 30.

${ }^{80}$ Reibl v Hughes, [1980] 2 S.C.R. 880, [1980] S.C.J. No. 105 at paras 2-3 [Reibl].

${ }^{81}$ Hopp v Lepp, [1980] 2 S.C.R. 192; [1980] 4 W.W.R. 645 at para 34. See also: Colleen M Flood, "Conundrums in Causation and Informed Medical Consent," (2000) 23 Advoc. Q. 217 at 219-220, citing Ciarlariello v Schacter, 1993 CarswellOnt 803, [1993] 2 S.C.R. 119 at para 36. In Quebec, the standard of care for disclosure is assessed from the perspective of the reasonable physician, a standard used in assessing physician's liability generally (Liss $v$. Watters, 2012 QCCA 257, 2012 CarswellQue 1038 at paras 74-76).

${ }^{82}$ Sarah Rodgers-Magnet, "Recent Developments in the Doctrine of Informed Consent to Medical Treatment - Re: Hopp v. Lepp and Reibl v. Hughes" (1980) 14 CCLT-ART 61 from s. "Extent of Disclosure" to "Hopp v. Lepp: An Objective Standard of Disclosure," inclusive; Robertson \& Picard, supra note 19 at 134-135; Martin Letendre, "Le Devoir du Médecin de Prévenir les Membres de la Famille d'un Patient Atteint d'une Maladie Génétique" (2004) 49 McGill L.J. 555 at 569.

${ }^{83}$ Philips-Nootens, supra note 60 at para 197.

${ }^{84}$ Stamos v Davies, [1985] 32 A.C.W.S. (2d) 165, 33 C.C.L.T. 1 at paras 25-26.

${ }^{85}$ Vasdani $v$ Sehmi, [1993] O.J. No. 44; 37 A.C.W.S. (3d) 856 at paras 32-34 [Vasdani].

${ }^{86}$ Robertson \& Picard, supra note 19 at 222-223. See also: Hollis v Birch at paras 23-26; Laferrière v Lawson [1991] 1 S.C.R. 541, [1991] R.R.A. 320 at para 10 [Lawson].

${ }^{87}$ Toth, supra note 39 at para 117.

${ }^{88}$ Vasdani, supra note 85 at para 40. 
${ }^{89}$ Mink v the University of Chicago, 460 F. Supp. 713 (N.D. Ill. 1978); Tresemer v Barke (1978) 86 Cal. App. 3d 656. 150 Cal. Rptr. 384; Molsbergen v the United States, 757 F.2d 1016; the latter decision concerns employer's liability for non-disclosure of risk but the analysis is much the same as that of the physician.

${ }^{90}$ Barker, supra note 51 at paras 126-128.

${ }^{91}$ Bain, supra note 40 at para 558; Toth, supra note 39 at para 117.

${ }^{92}$ Bain, supra note 40 at para 558.

${ }^{93}$ Rivtow Marine Ltd. v Washington Iron Works, 1973 CarswellBC 191, [1973] S.C.J. No. 126 at paras 17-20. See also Letendre, supra note 82 at 569.

${ }^{94}$ Robertson \& Picard, supra note 19 at 224.

${ }^{95}$ Bain, supra note 40 at paras 644-706.

${ }^{96}$ Reibl, supra note 80 at paras $22-23$.

${ }^{97}$ Philips-Nootens, supra note 60 at 149.

${ }^{98}$ Roel HP Wouters, "Is it Our Duty to Hunt Pathogenic Mutations?" (2018) 24:1 Trends in Molecular Medicine 36.

${ }^{99}$ Plaintiff's Complaint, Williams v Quest Diagnostics, Inc., (S.C. Ct. C.P.) (24 February 2016).

${ }^{100}$ Thorogood, Cook-Deegan \& Knoppers, supra note 41.

${ }^{101}$ Philips-Nootens, supra note 60 at 341. See also: Lawson, supra note 86.

102 Wei Estate v Dales [1998] O.J. No. 1411; 59 O.T.C. 98 at paras 61-65 [Wei Estate 1998]

${ }^{103}$ Robertson \& Picard, supra note 19 at p 417-19.

${ }^{104}$ Toth, supra note 39 at para 32.

${ }^{105}$ Philips-Nootens, supra note 60 at p 341.

${ }^{106}$ Toth, supra note 39 at para 117

${ }^{107}$ Wei Estate v Dales [2000] O.J. No. 2753; 135 O.A.C. 145.

${ }^{108}$ Burke-Pietramala v Samad 2004 BCSC 470 at para 18-22. See also: Kroll v Eli Lilly Canada Inc. [1996]

B.C.W.L.D. 2698; [1996] B.C.J. No. 3020 at para 21; Ibid at para. 25.

${ }^{109}$ McLintock v Alidina; 2011 ONSC 137; [2011] O.J. No. 49 at para 50 [McLintock].

${ }^{110}$ Patmore (Guardian ad litem of) $v$ Weatherston, 2000 CarswellOnt 2621; [2000] O.J. No. 2753 at paras 13-16;

Hebert $v$ Stanley, [1989] O.J. No. 1418; 17 A.C.W.S. (3d) 117 at para 16.

${ }^{111}$ McLintock, supra note 109 at paras 29, 50.

112 Wei Estate 1998, supra note 102 at para 4.

${ }^{113}$ Hamel c Haché [1999] R.R.A. 12, J.E. 99-301 at paras 5-6.

${ }^{114}$ St-Jean v Mercier [2002] 1 S.C.R. 491, 2002 SCC 15 at paras 26-27.

115 Ibid.

${ }^{116}$ Robertson \& Picard, supra note 19 at 417-419.

${ }^{117}$ Braun Estate v Vaughan 2000 CarswellMan 66; 3 W.W.R. 465, [2000] M.J. No. 63 at para 33 [Braun].

${ }^{118}$ Kahlon (Litigation Guardian of) v. Vancouver Coastal Health Authority 2009 BCSC 922; 2009 CarswellBC 1824 at para 176.

${ }^{119}$ Braun, supra note 117 at para 34.

${ }^{120}$ Toth, supra note 39 at paras 119, 125-127.

${ }^{121}$ Kahlon (Litigation Guardian of) v. Vancouver Coastal Health Authority 2009 BCSC 922; 2009 CarswellBC 1824 at para 188 , interpreting Toth.

${ }^{122}$ Braun, supra note 117.

${ }^{123}$ McLintock, supra note 109.

${ }^{124}$ Robertson \& Picard, supra note 19 at 442.

${ }^{125}$ Zawada v O'Kelly, [1996] A.W.L.D. 079; 1995 CarswellAlta 722 at paras 90-95.

${ }^{126}$ Bearden v Lee, [2003] O.J. No. 1261; [2003] O.T.C. 269 at para 124.

${ }^{127}$ Connell v Tanner, [2002] O.J. No. 1543; [2002] O.T.C. 484 at para 15.

${ }^{128}$ Joshi (Guardian ad litem of) $v$ Woolley, 1995 CarswellBC 185; [1995] B.C.W.L.D. 600 at paras 51, 88, 101, 162 [Joshi].

${ }^{129}$ Including her moral views on abortion, mental and physical health issues, and the consecration of her energies to the upbringing of her other children, including a child that required significant attendance due to his particular needs.

${ }^{130}$ Robertson \& Picard, supra note 19 at 444.

${ }^{131}$ Robertson \& Picard, supra note 19 at 442.

${ }^{132}$ Otten, Ellen, Mirjam Plantinga et al. "Is there a duty to recontact in light of new genetic technologies? A systematic review of the literature" (2015) 17 Genetics in Medicine 668. 
${ }^{133}$ Danya F Vears et al, "Analysis of VUS reporting, variant reinterpretation and recontact policies in clinical genomic sequencing consent forms" (2018) Eur J Hum Genet 1.

${ }^{134}$ Martin Letendre \& Beatrice Godard, "Expanding the physician's duty of care: a duty to recontact" (2004) 23 Med L 531 at 536.

${ }^{135}$ Karen L David et al, "Patient re-contact after revision of genomic test results: points to consider-a statement of the American College of Medical Genetics and Genomics (ACMG)" supra note 46.

${ }^{136}$ Kausmeyer et al, supra note 54.

${ }^{137}$ Griffen et al, supra note 54.

${ }^{138}$ John CS Dean et al. "Genetic registers in clinical practice: a survey of UK clinical geneticists" (2000) 37 J. Med. Genet. 636 at 639 .

${ }^{139}$ Smith v Jones 1999 (1 SCR 455).

${ }^{140}$ Watters $v$ White, 2012 QCCA 257; 2012 CarswellQue 1038 [Watters]. See generally Zawati \& Thorogood, supra note 8 .

${ }^{141}$ ABC v St George's Healthcare NHS Trust \& Ors, [2017] EWCA Civ 336.

${ }^{142}$ Ibid at para 24; see generally, Mitchell et al, supra note 8.

${ }^{143}$ Caparo Industries PLC v Dickman [1990] 1 All ER 568 at para 618.

${ }^{144}$ ABC v St George's Healthcare NHS Trust \& Ors, [2017] EWCA Civ 336, supra note 141 at paras 24 and 65-68.

${ }^{145}$ Karen L David et al, "Response to Knoppers et al." Genetics in Medicine (2019).

${ }^{146}$ Karen L David et al, "Patient re-contact after revision of genomic test results: points to consider — a statement of the American College of Medical Genetics and Genomics (ACMG)," supra note 46 at 770-771.

${ }^{147}$ Bombard, Brothers et al. supra note 11.

147 Ibid at 584.

${ }^{148}$ Ibid at 584-585.

149 Ibid at 586.

${ }^{150}$ Ibid at 585-586, 590.

${ }^{151}$ Ibid at 585 .

${ }^{152}$ Ibid at 591.

${ }^{153}$ Ibid at 588-591.

${ }^{154}$ Bartha Maria Knoppers, Adrian Thorogood and Ma'n H. Zawati. "Letter: Relearning the 3 R's? Reinterpretation, recontact, and return of genetic variants" Genetics in Medicine (2019).

${ }^{155}$ Angela Campbell and Kathleen Cranley Glass "The Legal Status of Clinical and Ethics Policies, Codes and Guidelines in Medical Practice and Research" 46 McGill L.J. 473 (2001) at 5.

${ }^{156}$ Ibid at 6.

${ }^{157}$ Ibid at 7.

${ }^{158}$ Stevens, Senner \& Marchant, supra note 10.

${ }^{159}$ Carrieri et al, supra note 44.

${ }^{160}$ Clayton et al, supra note 9 at 627.

${ }^{161}$ Watters, supra note 140 at paras 74-76.

${ }^{162}$ Letendre \& Godard, supra note 134, at 537-538.

${ }^{163}$ Bombard, Brothers et al supra note 11 at 586-588.

${ }^{164}$ Mark A Rothstein \& Gil Siegal, "Health information technology and physicians' duty to notify patients of new medical developments" (2011) 12 Hous J Health Pol 93 at 103.

${ }^{165}$ Bean, Laura et al, "Free the Data: One Laboratory's Approach to Knowledge-Based Genomic Variant Classification and Preparation for EMR Integration of Genomic Data" (2013) 34:9 Human Mutation 1183 at 1184. 166 Ibid.

167 Ibid.

${ }^{168}$ Bombard, Brothers et al, supra note 11.

169 Aronson et al. "Communicating new knowledge on previously reported genetic variants" Genet Med 2012:14(8):713-719 at 715. .

${ }^{170}$ Dean et al, supra note 138 at 637.

${ }^{171}$ Ibid at 638.

${ }^{172}$ Bartha Maria Knoppers \& Yann Joly, "Introduction: the why and whither of genomic data sharing" (2018) 137 Human Genetics 569 at 571.

${ }^{173}$ Dean et al, supra note 138 at 638.

${ }^{174}$ Marcus E Pembrey, "Genetic Registers" (1979) 54 Archives of Disease in Childhood 169 at 169. 
${ }^{175}$ Charles P Friedman et al, "Toward a science of learning systems: a research agenda for the high-functioning Learning Health System" 22:1 (2014) Journal of the American Medical Informatics Association 43.

${ }^{176}$ Charles P Friedman, Adam K Wong \& David Blumenthal, "Achieving a Nationwide Learning Health System" (2010) 2:57 Sci. Transl. Med. 1 at 1.

${ }^{177}$ Charles P Friedman \& Michael Rigby, "Conceptualising and creating a global learning health system" 82 (2013) International Journal of Medical Informatics e63 at e65.

${ }_{178}^{17 b i d .}$

${ }^{179}$ Friedman, Wong \& Blumenthal, supra note 177 at 2.

${ }^{180}$ Financial Stability Board, "Artificial intelligence and machine learning in financial services: Market Developments and Financial Stability Implications" (November 2017) at 13-14.

${ }^{181}$ Ibid at $18-20$.

182 UK Competition and Markets Authority, "The Commercial Uses of Consumer data" (2015) CMA 38 at 53-62; Kai Jia et al, "The Application of Artificial Intelligence at Chinese Digital Platform Giants: Baidu, Alibaba and Tencent" (2018) ETLA Reports No 81 at 6.

${ }^{183}$ Deloitte, "Big Data and Analytics in the Automotive Industry: Automotive Analytics Thought Piece" (2015), Creative Studio Deloitte London; SAS Institute. "The Connected Vehicle: Big Data, Big Opportunities" (2015) at 27.

${ }^{184}$ Friedman et al, supra note 176 at 44 .

${ }^{185}$ Marchant \& Lindor, "Personalized medicine and genomic malpractice", supra note 3.

${ }^{186}$ Gregory Costain et al, "Periodic reanalysis of whole-genome sequencing data enhances the diagnostic advantage over standard clinical genetic testing" (2018) 26:5 Eur J Hum Genet 740; Mahdi Sarmady \& Ahmad Abou Tayoun, "Need for Automated Interactive Genomic Interpretation and Ongoing Reanalysis" (2018) JAMA Pediatr, online: <https://jamanetwork.com/journals/jamapediatrics/fullarticle/2703917>.

${ }^{187}$ Rothstein \& Siegal, supra note 165 at 132.

${ }^{188}$ Ibid at 130.

${ }^{189}$ Yuval Noah Harari, 21 Lessons for the 21st Century (Random House 2018) at 21-22. 